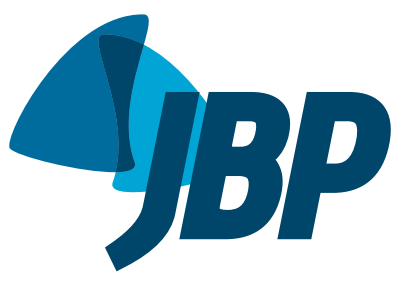

\title{
Cross-cultural adaptation of the Cambridge Pulmonary Hypertension Outcome Review for use in patients with pulmonary hypertension in Colombia
}

\author{
Claudio Villaquirán ${ }^{1,2, a}$, Socorro Moreno ${ }^{3, b}$, Rubén Dueñas $4, c$, Paola Acuña ${ }^{5, d}$, \\ Juan Ricardo Lutz ${ }^{2, e}$, Jeanette Wilburn ${ }^{6, f}$, Alice Heaney ${ }^{6,9}$
}

1. Unidad de Enfermedades Respiratorias, Departamento de Medicina Interna, Hospital Universitario San Ignacio, Pontificia Universidad Javeriana, Bogotá, Colombia.

2. Clínicos IPS, Bogotá, Colombia.

3. Departamento de Epidemiología Clínica y Bioestadística, Pontificia Universidad Javeriana, Bogotá, Colombia.

4. Fundación Clinica Shaio. Bogotá, Colombia.

5. Departamento de Medicina Interna, Pontificia Universidad Javeriana, Bogotá, Colombia.

6. Galen Research, Manchester, United Kingdom.

a. (D) http://orcid.org/0000-0002-3743-6268

b. (D) http://orcid.org/0000-0002-4119-4409

c. (D) http://orcid.org/0000-0002-2120-6353

d. (D) http://orcid.org/0000-0003-4692-181X

e. (iD) http://orcid.org/0000-0001-6034-0005

f. (D) http://orcid.org/0000-0002-9168-5716

g. (D) http://orcid.org/0000-0002-4534-6705

Submitted: 16 November 2018

Accepted: 20 January 2019.

Study carried out at the Unidad de Enfermedades Respiratorias,

Departamento de Medicina Interna

Hospital Universitario San Ignacio,

Pontificia Universidad Javeriana, at

Fundación Clínica Shaio, and at Clínicos

IPS, Bogotá, Colombia.

\section{ABSTRACT}

Objective: To conduct a cross-cultural adaptation of the Cambridge Pulmonary Hypertension Outcome Review (CAMPHOR) as an instrument to evaluate the perception of symptoms, functional limitation, and health-related quality of life ( $\mathrm{HROOL}$ ) in subjects diagnosed with pulmonary arterial hypertension (PAH) or chronic thromboembolic pulmonary hypertension (CTEPH) in Colombia. Methods: The adaptation process involved 3 phases: translation, cognitive debriefing interviews, and a validation survey. To evaluate the psychometric properties, we recruited individuals $\geq 18$ years of age who had been diagnosed with PAH or CTEPH to take part in the latter two stages of the adaptation process. All individuals were being followed on an outpatient basis by the pulmonary hypertension programs at Hospital Universitario San Ignacio, Fundación Clínica Shaio, and Clínicos IPS, all located in the city of Bogotá, Colombia. Results: A Spanish-language version of the CAMPHOR was developed for use in Colombia. The internal consistency was excellent for the symptoms, functioning, and quality of life scales (Cronbach's alpha coefficients of 0.92, 0.87, and 0.93, respectively). Testretest reliability was above 0.70 . The evaluation of the convergent validity and known group validity of the CAMPHOR scales confirmed that there were moderate and strong correlations with the related constructs of the Medical Outcomes Study 36-item ShortForm Health Survey, version 2, as well as showing their capacity to discriminate disease severity. Conclusions: The Spanish-language version of the CAMPHOR developed for use in Colombia was the result of a translation and cultural adaptation process that allows us to consider it equivalent to the original version, having shown good psychometric properties in the study sample. Therefore, its use to assess the impact of interventions on the HRQoL of patients with PAH or CTEPH is recommended, in research and clinical practice.

Keywords: Quality of life; Hypertension, pulmonary; Pulmonary embolism; Psychometrics.

\section{INTRODUCTION}

Pulmonary hypertension (PH) is a common hemodynamic condition defined by a mean pulmonary artery pressure greater than or equal to $25 \mathrm{mmHg}$, as determined by right heart catheterization.

$\mathrm{PH}$ accompanies multiple pathological conditions, which are classified into 5 large groups according to the physiopathological mechanism involved ${ }^{(2)}$ :

1. Pulmonary arterial hypertension (PAH)

2. $\mathrm{PH}$ associated with left heart disease

3. $\mathrm{PH}$ associated with lung disease and/or hypoxia

4. Chronic thromboembolic PH (CTEPH)

5. $\mathrm{PH}$ associated with multifactorial mechanisms

The most common causes of $\mathrm{PH}$ are group 2 and group

3 conditions, in which $\mathrm{PH}$ confers a worse prognosis despite its mild severity and slow progression. When $\mathrm{PH}$ belongs to group 2 or group 3, it is not considered a separate disease, and, therefore, treatment is that of the underlying disease. ${ }^{(3)}$

In contrast, $\mathrm{PAH}$ and $\mathrm{CTEPH}$ (groups 1 and 4 ) are considered to be uncommon ( $5 \%$ and $4 \%$, respectively), high mortality diseases of the pulmonary circulation, resulting from pulmonary vascular remodeling and vascular bed obstruction, which, over time, cause right ventricular dysfunction and failure. (1,3,4) $^{(1,0)}$

Knowledge of pathophysiological mechanisms has made it possible to change the clinical course of a disease that had a mean survival of 2.8 years and have multiple therapeutic options that can increase life expectancy, restore exercise tolerance, improve the

Correspondence to:

Claudio Villaquirán. Unidad de Enfermedades Respiratorias, Departamento de Medicina Interna, Hospital Universitario San Ignacio, Carrera 7, 40-62, sexto piso,

Bogotá, Colombia.

Tel./Fax: 571 594-6175. E-mail:claudiovillaquiran@gmail.com

Financial support: None. 
hemodynamic profile, and improve health-related quality of life (HRQoL). ${ }^{(3-6)}$

Most medications for treating PAH and CTEPH have been demonstrated to be effective and safe on the basis of endpoints such as increases in six-minute walk distance, improvements in hemodynamic parameters, improvements in functional class, and reductions in biomarkers (natriuretic peptide). ${ }^{(3,6-11)}$ Those endpoints have been shown not necessarily to correlate with improvements in symptoms, HRQoL, or life expectancy; therefore, experts recommend that endpoints that directly evaluate morbidity/mortality and improvements in HRQoL be considered, so that new molecules can be approved and included. ${ }^{(12,13)}$

There is a significant impact on HRQoL in patients diagnosed with PAH or CTEPH, ${ }^{(14,15)}$ as a result of the physical and functional limitations of the disease, comorbidities, and the therapy used.

This impact on HRQoL has been described using tools such as the Borg scale, the Saint George's Respiratory Questionnaire, the Minnesota Living with Heart Failure Questionnaire, the Medical Outcomes Study 36-item Short-Form Health Survey (SF-36), the Nottingham Health Profile, the European Quality of Life-5 Dimensions questionnaire, ${ }^{(15)}$ and emPHasis-10. ${ }^{(16)}$ Until recently, the first and only questionnaire developed specifically to assess HRQoL in PH was the Cambridge Pulmonary Hypertension Outcome Review (CAMPHOR). ${ }^{(17)}$ This self-administered tool developed in the United Kingdom was the result of in-depth interviews conducted with patients with $\mathrm{PH}$ and has 3 scales: symptoms (25 questions); functioning (15 questions); and quality of life (25 questions) -with higher scores corresponding to a greater impact of the disease on patient HRQoL.

The CAMPHOR has been demonstrated to be a tool that yields valid, reliable, and sensitive results for evaluating baseline HRQoL and post- intervention HRQoL in subjects with PAH or CTEPH, ${ }^{(15,17,18)}$ and, therefore, it has undergone several semantic and cultural adaptation processes, all of which resulted in versions with good psychometric properties, similar to those of the original version. ${ }^{(19-26)}$

The CAMPHOR has been adapted and validated for use in the United States, (19) Canada, (20) Australia/ New Zealand, (21) Germany/Switzerland/Austria, (22) Sweden, (23) Portugal, (24) the Netherlands, ${ }^{(25)}$ and recently in Spain, ${ }^{(26)}$ with all versions having good psychometric properties.

Currently in Colombia, there is no instrument that allows us to evaluate the perception of patients with PAH or CTEPH regarding the effects of the disease on different aspects of their lives, which we consider essential for providing comprehensive treatment and the necessary support for each patient. Therefore, the main objective of this study was to conduct a cultural (semantic and psychometric) adaptation of the CAMPHOR as an instrument to measure the perception of symptoms, functional limitation, and
HRQoL in subjects diagnosed with PAH or CTEPH in Colombia.

\section{METHODS}

This study was approved by the Research Ethics Committees of Hospital Universitario San Ignacio, Fundación Clínica Shaio, and Clínicos IPS, all of which are located in the city of Bogotá. The adaptation process to develop a Spanish-language version of the CAMPHOR for use in Colombia consisted of 3 phases: translation of the questionnaire; cognitive debriefing interviews; and a validation survey. Patients were invited to participate in phases 2 and 3 if they were $\geq 18$ years of age, had been diagnosed with $\mathrm{PAH}$ or $\mathrm{CTEPH}$, and were able to complete the forms.

The CAMPHOR was translated using the two-panel method, (27) which consisted, first, of a bilingual panel, which was responsible for producing a first Spanishlanguage version of the questionnaire; was formed of local individuals, who were fluent in English and Spanish and had no history of professional clinical practice; and was accompanied by a representative of Galen Research (the holders of the intellectual property of the CAMPHOR). Second, a lay panel was formed including local individuals with an average level of education and no knowledge of English, who were responsible for determining whether the phrasing and the words chosen for each item in the translated version were acceptable and sounded natural.

Face-to-face semi-structured interviews were conducted in accordance with a protocol provided by Galen Research, in which respondents filled out the questionnaire, while a researcher observed the uncertainties created by the items and subsequently asked respondents about item comprehensibility and aspects of living with $\mathrm{PH}$. The objective of those interviews was to evaluate the applicability, relevance, comprehensibility, semantic equivalence, and technical equivalence of the Spanish-language version of the CAMPHOR developed by the two panels for use in Colombia.

The Spanish-language version of the CAMPHOR developed for use in Colombia underwent a psychometric evaluation to determine whether the results obtained were reliable, consistent, and valid. The instrument was administered twice (test-retest), approximately two weeks apart, to 81 patients who met the selection criteria and were recruited by convenience sampling.

Descriptive statistics for continuous variables are expressed as mean (standard deviation), median (interquartile range), and percentage of patients scoring the minimum and maximum possible scores. ${ }^{(28,29)}$ Internal consistency was evaluated by using Cronbach's alpha coefficient, for which a value greater than 0.70 is evidence of satisfactory reliability and indicates an appropriate relationship of the items with one another, allowing their combination into a scale. Spearman's correlation coefficient was 
calculated in order to evaluate the reliability of the scales over time (test-retest). A value greater than or equal to 0.70 indicates a low degree of random error in measurement of the new Spanish-language version of the instrument.

Convergent validity was determined by evaluating the level of association between the CAMPHOR and SF-36v2 scale scores for the first administration (T1), by using Spearman's correlation coefficient. Although higher scores on the SF-36v2 indicate better health status, the same is not true for CAMPHOR scores.

In order to determine known group validity, the factor used was perceived symptom severity. Nonparametric tests for independent samples (Mann-Whitney $U$ test) were used to test differences in the CAMPHOR scores between the groups. Values of $p<0.05$ were considered statistically significant.

\section{RESULTS}

A bilingual panel consisting of 6 women between 33 and 54 years of age, who were fluent in English and had no history of clinical practice, translated the original English-language version of the CAMPHOR into Spanish. In general, the panel considered that the instructions and most of the questions were clear and easy to translate. Translation alternatives for each item were discussed until consensus on conceptual equivalence was achieved, and more than one alternative was provided for some items so that the lay panel could choose among them. Two items with significant colloquial components (\#23 in the symptoms scale ["I feel hopeless"] and \#10 in the quality of life scale ["It feels like my body has let me down"]) were found hard to translate because of difficulties in conveying the idea of the original language ("hopelessness" and "disappointment with one's body") into Spanish. The translation sought to maintain conceptual equivalence, and the lay panel selected the best alternative for each one.

The lay panel (which consisted of 3 women and 2 men who were between 25 and 53 years of age and had no knowledge of English) was responsible for reviewing the translations, that is, the phrasing and language used, as well as for selecting among the translation alternatives proposed by the bilingual panel those that were most appropriate. Some minor changes were made to three of the items to facilitate comprehension and make them sound more natural in Spanish in Colombia.

After the version of the instrument had been developed and consolidated by the two panels, in-depth interviews were conducted with 11 subjects diagnosed with PAH or CTEPH. The subjects completed the questionnaire in a mean time of 11 minutes (standard deviation \pm 3 ). During the interviews, difficulties were identified for the YES/NO response options in the section on quality of life because the NO option created a double negative in the item, and, therefore, the response options were changed to True/
False. However, the questionnaire was considered understandable, clear, and easy to complete.

Psychometric evaluation was performed with 81 subjects diagnosed with PAH or CTEPH. The questionnaire was administered at 2 time points 15 days apart (T1 and T2). In addition to the CAMPHOR, participants completed the SF-36 version 2 (SF-36v2) at one time point (T1).

The demographic characteristics of participants are presented in Table 1 . The mean age of subjects was $49 \pm 15$ years, with females predominating (female-to-male ratio, 5:1), and, although most subjects described the severity of their hypertension as moderate-severe $(79 \%)$, it is striking that one third of them were still occupationally active (27\%) or still performed household chores (37\%).

The scores on the Spanish-language version of the CAMPHOR developed for use in Colombia, at T1 and T2, as well as the SF-36v2 scale scores at T1, are presented in Table 2. High ceiling effects were observed for some SF-36v2 scales (i.e., a large number of patients scored the maximum score), which could suggest that this measure of health status is not suitably targeted at patients with $\mathrm{PH}$. In contrast, for the CAMPHOR, there was no evident ceiling or floor effect (i.e., less than $10 \%$ reached the minimum or maximum score).

Cronbach's alpha coefficients for internal consistency are shown in Table 3. For all CAMPHOR scales, Cronbach's alpha coefficients were above 0.80 , indicating a good interrelationship among the items in each scale.

For the sake of reproducibility, patients who reported or experienced a change in their perception of their disease severity between T1 and T2 were excluded from the analysis. The test-retest reliability (Table 4) for each of the 3 CAMPHOR scales (symptoms, functioning, and quality of life) showed a strong correlation ( $0.79 ; 0.79$, and 0.84 , respectively) and was close to the value of 0.85 found in the study that developed the original instrument. The stable values observed result in low likelihood of random error in measurement, adjusting for changes in patient health status over time. The values obtained for the CAMPHOR scales are markedly higher than those obtained for other instruments.

Table 5 shows the correlations between the CAMPHOR and SF-36v2 scales at T1. As expected, the CAMPHOR symptoms and functioning scales had strong correlations with the SF-36v2 physical functioning and role-physical scales, respectively. The CAMPHOR quality of life scale score had moderate to strong associations with the SF-36v2 scale scores, which indicates that many factors influence quality of life.

For known-group analysis, perceived disease severity was classified as "Mild/Moderate" and "Fairly severe/Very severe" because of the small number of subjects belonging to the "Mild" and "Very severe" groups. Figure 1 shows the differences in CAMPHOR 
Cross-cultural adaptation of the Cambridge Pulmonary Hypertension Outcome

Review for use in patients with pulmonary hypertension in Colombia

Table 1. Demographic characteristics of participants. ${ }^{a}$

\begin{tabular}{|c|c|c|}
\hline Variable & $\begin{array}{l}\text { Cognitive debriefing interviews } \\
\qquad(\mathrm{n}=11)\end{array}$ & $\begin{array}{l}\text { Validation survey } \\
\qquad(\mathrm{n}=\mathbf{8 1})\end{array}$ \\
\hline Age, years & $38 \pm 16$ & $49 \pm 15$ \\
\hline Range & $18-69$ & $18-79$ \\
\hline \multicolumn{3}{|l|}{ Gender } \\
\hline Female & $9(82)$ & $68(84)$ \\
\hline Male & $12(18)$ & $13(16)$ \\
\hline \multicolumn{3}{|l|}{ Marital status } \\
\hline Single & $5(45)$ & $25(31)$ \\
\hline Married/steady partner & $6(55)$ & $46(57)$ \\
\hline Divorced & $0(0)$ & $8(10)$ \\
\hline Widowed & $0(0)$ & $2(2)$ \\
\hline \multicolumn{3}{|l|}{ Work activity } \\
\hline Works full time & $5(45.0)$ & $10(12.3)$ \\
\hline Works part time & $0(0)$ & $12(14.8)$ \\
\hline Housewife & $0(0)$ & $30(37)$ \\
\hline Pensioner & $2(18.0)$ & $18(22.2)$ \\
\hline Retired due to illness & $1(9.0)$ & $4(4.9)$ \\
\hline Unemployed & $1(9.0)$ & $3(3.7)$ \\
\hline Student & $1(9.0)$ & $2(2.5)$ \\
\hline Other & $1(9.0)$ & $2(2.5)$ \\
\hline \multicolumn{3}{|l|}{ PH severity } \\
\hline Mild & $1(9.0)$ & $10(12)$ \\
\hline Moderate & $4(36.0)$ & $33(40.7)$ \\
\hline Severe & $5(45.0)$ & $31(38.3)$ \\
\hline Very severe & $1(9.0)$ & $6(7.4)$ \\
\hline
\end{tabular}

alues expressed as mean \pm SD or as $\mathrm{n}(\%)$.

Table 2. Questionnaire descriptive scores (time points 1 and 2).

\begin{tabular}{|c|c|c|c|c|c|}
\hline Questionnaire & $\mathrm{n}$ of patients & $\begin{array}{l}\text { Median score } \\
\text { (IQR) }\end{array}$ & $\begin{array}{c}\text { Min-max } \\
\text { possible score }\end{array}$ & $\begin{array}{l}\% \text { of patients } \\
\text { scoring the } \\
\text { minimum score }\end{array}$ & $\begin{array}{l}\% \text { of patients } \\
\text { scoring the } \\
\text { maximum } \\
\text { score }\end{array}$ \\
\hline \multicolumn{6}{|l|}{ CAMPHOR (T1) } \\
\hline Symptoms & 80 & $8(5-13)$ & $0-24$ & 3.7 & 0 \\
\hline Functioning & 81 & $9(5-14)$ & $0-26$ & 4.9 & 0 \\
\hline Quality of life & 81 & $5(3-13)$ & $0-22$ & 7.4 & 0 \\
\hline \multicolumn{6}{|l|}{ CAMPHOR (T2) } \\
\hline Symptoms & 77 & $7(3-13)$ & $0-23$ & 2.5 & 0 \\
\hline Functioning & 77 & $10(6-15)$ & $0-25$ & 4.9 & 0 \\
\hline Quality of life & 77 & $5(2-12)$ & $0-24$ & 6.5 & 0 \\
\hline \multicolumn{6}{|l|}{ SF-36V2 (T1) } \\
\hline Physical functioning & 79 & $50(30-65)$ & $5-100$ & 0 & 3.7 \\
\hline Role-physical & 79 & $56(38-81)$ & $0-100$ & 2.5 & 12.3 \\
\hline Bodily pain & 79 & $51(41-72)$ & $0-100$ & 2.5 & 14.8 \\
\hline General health & 79 & $50(35-67)$ & $5-100$ & 0 & 1.2 \\
\hline Vitality & 79 & $56(44-75)$ & $6-100$ & 0 & 7.4 \\
\hline Social functioning & 79 & $75(50-100)$ & $13-100$ & 0 & 32.1 \\
\hline Role-emotional & 79 & $83(50-100)$ & $0-100$ & 3.7 & 43.2 \\
\hline Mental health & 79 & $75(55-95)$ & $15-100$ & 0 & 21.0 \\
\hline
\end{tabular}

IQR: interquartile range; CAMPHOR: Cambridge Pulmonary Hypertension Outcome Review; T1: time point 1; T2: time point 2; and SF-36v2: Medical Outcome Study 36-Item Short Form Health Survey, version 2

scale scores by disease severity group, with patients with more severe $\mathrm{PH}$ scoring higher on each scale. Each scale of the Spanish-language version of the
CAMPHOR developed for use in Colombia was able to distinguish between patients according to disease severity. 


\section{DISCUSSION}

The process of adapting an instrument prepared in one language and culture for use in another is a major methodological challenge in which, in addition to making an equivalent translation, it is necessary to conduct a psychometric evaluation process that

Table 3. Cronbach's alpha coefficients.

\section{CAMPHOR scale}

Symptoms

Functioning Time point 1

Quality of life

CAMPHOR: Cambridge Pulmonary Hypertension

can ensure that the instrument and the constructs that it tries to measure really work in similar way between the populations of interest. ${ }^{(30)}$

Since the CAMPHOR is the first instrument specifically developed to evaluate HRQoL in $\mathrm{PH}$, it has been the one most widely used in clinical studies, and there have been several publications describing in detail the process of culturally adapting it for use in different countries. ${ }^{(19-26)}$ It is important to point out that, in the adapted versions, good psychometric properties, similar to those of the original version, were achieved.

The psychometric properties of the Spanish-language version of the CAMPHOR developed for use in Colombia were evaluated in a non-probabilistic sample of 81

Table 4. Test-retest reliability.

\begin{tabular}{lccc} 
Test-retest reliability & $\begin{array}{c}\text { Symptoms } \\
(\mathbf{n}=\mathbf{5 0})\end{array}$ & $\begin{array}{c}\text { CAMPHOR } \\
\text { Functioning } \\
(\mathbf{n}=\mathbf{5 1})\end{array}$ & $\begin{array}{c}\text { Quality of life } \\
(\mathbf{n}=\mathbf{5 1})\end{array}$ \\
\hline Correlation coefficient & 0.79 & 0.79 & 0.84 \\
\hline
\end{tabular}

Table 5. Coefficients of correlation between the Cambridge Pulmonary Hypertension Outcome Review and the Medical Outcomes Study 36-Item Short Form Healthy Survey, version 2.*

\begin{tabular}{lccc} 
& SF-36v2 & CAMPHOR & \\
Physical functioning & Symptoms & Functioning & Quality of life \\
Role-physical & -0.76 & -0.76 & -0.56 \\
Bodily pain & -0.73 & -0.72 & -0.74 \\
General health & -0.57 & -0.50 & -0.62 \\
Vitality & -0.67 & -0.55 & -0.55 \\
Social functioning & -0.77 & -0.53 & -0.67 \\
Role-emotional & -0.66 & -0.48 & -0.74 \\
Mental health & -0.55 & -0.34 & -0.59 \\
\hline
\end{tabular}

CAMPHOR: Cambridge Pulmonary Hypertension Outcome Review; and SF-36v2: Medical Outcomes Study 36 Item Short Form Healthy Survey, version 2. *All correlations were significant $(p<0.01)$.
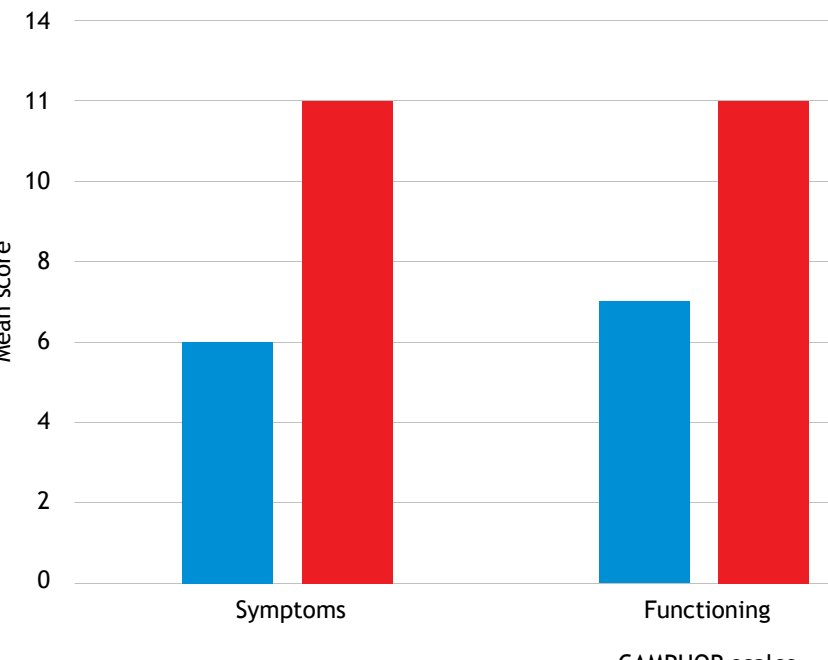
subjects with PAH or CTEPH of different severities. The demographic characteristics of our population are similar to those of the population involved in the study that developed the original CAMPHOR and those of the populations involved in the different studies that culturally adapted and validated the CAMPHOR for use in other countries. ${ }^{19-26)}$

The Cronbach's alpha coefficients for the symptoms, functioning, and quality of life scales at T1 and T2 were above the minimum required value of 0.70 (strong correlation), being considered appropriate and similar to those found for the original Englishlanguage version, ${ }^{(18)}$ which confirms the good internal consistency of the Spanish-language version of the CAMPHOR developed for use in Colombia.

The percentage of patients scoring the minimum and maximum possible scores on this Spanish-language version of the CAMPHOR developed for use in Colombia was small, which means that the measurement of health status in patients with PAH or CTEPH is appropriate and supports the use of the instrument for post-intervention evaluation of changes.

The evaluation of convergent validity allows us to estimate the association between two constructs that are theoretically related to one another. In this study, the scales of the Spanish-language version of the CAMPHOR developed for use in Colombia were correlated with those of the SF-36v2. The CAMPHOR symptoms and functioning scales were found to have a strong correlation with the SF-36v2 physical functioning scale ( 0.76 for both) and role-physical scale ( 0.72 for both). The quality of life scale of the Spanish-language version of the CAMPHOR developed for use in Colombia showed strong correlations with the SF-36v2 role-physical and social functioning scales ( 0.74 for both), confirming that the two aspects are both affected by the disease and are associated with deterioration in quality of life.

The tool was able to discriminate between patients with mild/moderate disease and those with severe/very severe disease, with sicker patients scoring higher, which provides evidence of known group validity.

There are some potential limitations to our study. Although the participating subjects were recruited from specialized centers, they may not be necessarily representative of the general population in Colombia because of the sampling type, which may introduce a sampling bias. However, the bulk of patients diagnosed with $\mathrm{PH}$ are not usually managed in general hospitals or private practices, but rather in centers similar to ours, which are considered expert or "referral" centers for the management of the disease, and, therefore, the participating subjects could be considered representative.

Only clinically stable patients being treated on an outpatient basis were invited to participate in this study, and those who had very severe disease, were clinically unstable, and were hospitalized were excluded. Given that the study was not intended to evaluate the impact of PAH or CTEPH on quality of life, but rather to conduct a cultural and semantic adaptation of the CAMPHOR, we do not consider that the exclusion of those subjects will have affected this process.

Prospective studies using the Spanish-language version of the CAMPHOR developed for use in Colombia are needed to determine the impact of the disease on quality of life in our population.

The findings of this study suggest that the Spanishlanguage version of the CAMPHOR developed for use in Colombia as a self-administered, easy-to-use instrument was the result of a translation and cultural adaptation process that allows us to consider it conceptually, semantically, and technically equivalent to the original version, having shown good psychometric properties in a sample of patients between 18 and 79 years of age. Therefore, it can be used in research and clinical practice to assess the impact of health interventions on the HRQoL of patients with $\mathrm{PAH}$ or $\mathrm{CTEPH}$ in Colombia.

\section{ACKNOWLEDGMENTS}

We are especially grateful to Adriana Garavito and Ludwing Sammer for supporting this initiative, the Department of Communication and Language of the Pontificia Universidad Javeriana for its assistance with the process, and the Colombian Association of Patients with Pulmonary Hypertension, who are the reason for this and other projects.

\section{REFERENCES}

1. Hoeper MM, Bogaard HJ, Condliffe R, Frantz R, Khanna D, Kurzyna $\mathrm{M}$, et al. Definitions and diagnosis of pulmonary hypertension. J Am Coll Cardiol. 2013;62(25 Suppl):D42-50. https://doi.org/10.1016/j. jacc.2013.10.032

2. Simonneau G, Gatzoulis MA, Adatia I, Celermajer D, Denton C Ghofrani $A$, et al. Updated clinical classification of pulmonary hypertension. J Am Coll Cardiol. 2013;62(25 Suppl):D34-41. https:// doi.org/10.1016/j.jacc.2013.10.029

3. Galiè N, Humbert M, Vachiery JL, Gibbs S, Lang I, Torbicki A, et al. 2015 ESC/ERS Guidelines for the diagnosis and treatment of pulmonary hypertension: The Joint Task Force for the Diagnosis and Treatment of Pulmonary Hypertension of the European Society of Cardiology (ESC) and the European Respiratory Society (ERS): Endorsed by: Association for European Paediatric and Congenital Cardiology (AEPC), International Society for Heart and Lung Transplantation (ISHLT). Eur Respir J. 2015;46(4):903-75. https://doi.

org/10.1183/13993003.01032-2015

4. Peacock AJ, Murphy NF, McMurray JJ, Caballero L, Stewart S. An epidemiologicalstudy of pulmonary arterial hypertension. Eur Respir J. 2007;30(1):104-9. https://doi.org/10.1183/09031936.00092306

5. Galiè N, Corris PA, Frost A, Girgis RE, Granton J, Jing ZC, et al Updated treatment algorithm of pulmonary arterial hypertension. $J$ Am Coll Cardiol. 2013;62(25 Suppl):D60-72. https://doi.org/10.1016/j. jacc.2013.10.031

6. Robin ED. The kingdom of the near-dead. The shortened unnatural life history of primary pulmonary hypertension. Chest. 1987;92(2):330-4 https://doi.org/10.1378/chest.92.2.330

7. Barst Rj, Rubin LJ, Long WA, MCGoon MD, Rich S, Badesch $D B$, et al. A comparison of continuous intravenous epoprostenol (prostacyclin) with conventional therapy for primary pulmonary hypertension. N Engl J Med. 1996 1;334(5):296-301. https://doi 
org/10.1056/NEJM199602013340504

8. Rubin LJ, Badesch DB, Barst RJ, Galie N, Black CM, Keogh A, et al. Bosentan therapy for pulmonary arterial hypertension. N Engl $J$ Med. 2002;346(12):896-903. https://doi.org/10.1056/NEJMoa012212

9. Kuschner WG Sildenafil citrate therapy for pulmonary arterial hypertension. N Engl J Med. 2005;354(10):1091-3; author reply 10913. https://doi.org/10.1056/NEJMc053442

10. Olschewski H, Simonneau G, Galiè N, Higenbottam T, Naeije R, Rubin $\mathrm{LJ}$, et al. Inhaled iloprost for severe pulmonary hypertension. N Engl J Med. 2002;347(5):322-9. https://doi.org/10.1056/NEJMoa020204

11. Galiè N, Olschewski H, Oudiz RJ, Torres F, Frost A, Ghofrani HA, et al. Ambrisentan for the treatment of pulmonary arterial hypertension: results of the ambrisentan in pulmonary arterial hypertension, randomized, double-blind, placebo-controlled, multicenter, efficacy (ARIES) study 1 and 2. Circulation. 2008;117(23):3010-9. https://doi. org/10.1161/CIRCULATIONAHA.107.742510

12. McLaughlin W, Badesch DB, Delcroix M, Fleming TR, Gaine SP, Galiè N, et al. End points and clinical trial design in pulmonary arterial hypertension. J Am Coll Cardiol. 2009;54(1 Suppl):S97-107. https:// doi.org/10.1016/i.jacc.2009.04.007

13. Studer SM, Gilkin RJ Jr. Clinical trial designs in PAH: shifting from functional measurements to long-term clinical outcomes. Am J Manag Care. 2014;20(6 Suppl):S115-22.

14. Gu S, Hu H, Dong H. Systematic Review of Health-Related Quality of Life in Patients with Pulmonary Arterial Hypertension. Pharmacoeconomics. 2016;34(8):751-70. https://doi.org/10.1007/ s40273-016-0395-y

15. Mathai SC, Ghofrani HA, Mayer E, Pepke-Zaba J, Nikkho S, Simonneau G. Quality of life in patients with chronic thromboembolic pulmonary hypertension. Eur Respir J. 2016;48(2):526-37. https://doi. org/10.1183/13993003.01626-2015

16. Yorke J, Corris P, Gaine S, Gibbs JS, Kiely DG, Harries C, et al. emPHasis-10: development of a health-related quality of life measure in pulmonary hypertension. Eur Respir J. 2014;43(4):1106-13. https:// doi.org/10.1183/09031936.00127113

17. McKenna SP, Doughty N, Meads DM, Doward LC, Pepke-Zaba J. The Cambridge Pulmonary Hypertension Outcome Review (CAMPHOR): a measure of health-related quality of life and quality of life for patients with pulmonary hypertension. Qual Life Res. 2006;15(1):103-15. https://doi.org/10.1007/s11136-005-3513-4

18. Meads DM, McKenna SP, Doughty N, Das C, Gin-Sing W, Langley $J$, et al. The responsiveness and validity of the CAMPHOR Utility Index. Eur Respir J. 2008;32(6):1513-9. https://doi. org/10.1183/09031936.00069708

19. Gomberg-Maitland M, Thenappan T, Rizvi K, Chandra S, Meads DM, McKenna SP. United States validation of the Cambridge Pulmonary Hypertension Outcome Review (CAMPHOR). J Heart
Lung Transplant. 2008;27(1):124-30. https://doi.org/10.1016/j. healun.2007.10.004

20. Coffin D, Duval K, Martel S, Granton J, Lefebvre MC, Meads DM, et al. Adaptation of the Cambridge Pulmonary Hypertension Outcome Review (CAMPHOR) into French-Canadian and English-Canadian. Can Respir J. 2008;15(2):77-83. https://doi.org/10.1155/2008/767126

21. Ganderton L, Jenkins S, McKenna SP, Gain K, Fowler R, Twiss J, et al. Validation of the Cambridge Pulmonary Hypertension Outcome Review (CAMPHOR) for the Australian and New Zealand population. Respirology. 2011;16(8):1235-40. https://doi.org/10.1111/j.14401843.2011.02030.x

22. Cima K, Twiss J, Speich R, McKenna SP, Grünig E, Kähler CM, et al. The German adaptation of the Cambridge Pulmonary Hypertension Outcome Review (CAMPHOR). Health Qual Life Outcomes. 2012;10:110. https://doi.org/10.1186/1477-7525-10-110

23. Selimovic N, Rundqvist B, Kiörk E, Viriden J, Twiss J, McKenna SP. Adaptation and validation of the Cambridge pulmonary hypertension outcome review for Sweden. Scand J Public Health. 2012:40(8):77783. https://doi.org/10.1177/1403494812464445

24. Reis A Twiss J Vicente M, Goncalves F, Carvalho L, Meireles J et al. Portuguese validation of the Cambridge pulmonary hypertension outcome review (CAMPHOR) questionnaire. Health Qual Life Outcomes. 2016:14(1):110. https://doi.org/10.1186/s12955-0160513-8

25. Wapenaar $M$, Twiss J, Wagenaar $M$, Seijkens $P$, van den Toorn $L$, Stepanous J, et al. Adaptation and validation of the Cambridge Pulmonary Hypertension Outcome Review (CAMPHOR) for the Netherlands. Neth Heart J. 2016;24(6):417-24. https://doi. org/10.1007/s12471-016-0849-z

26. Aguirre-Camacho A, Stepanous J, Blanco-Donoso LM, MorenoJiménez B, Wilburn J, González-Saiz $L$, et al. Adaptation and Validation of the Cambridge Pulmonary Hypertension Outcome Review (CAMPHOR) for Use in Spain. Rev Esp Cardiol (Engl Ed). 2017;70(6):467-473. https://doi.org/10.1016/..recesp.2016.11.006

27. Mckenna SP, Doward LC. The translation and cultural adaptation of patient-reported outcome measures. Value Health. 2005;8(2):89-91. https://doi.org/10.1111/j.1524-4733.2005.08203.x

28. Lang T, Altman D. Basic statistical reporting for articles published in biomedical journals: the "Statistical Analyses and Methods in the Published Literature" or the SAMPL Guidelines. Int J Nurs Stud. 2015;52(1):5-9. https://doi.org/10.1016/.ijnurstu.2014.09.006

29. Bellolio M, Serrano L, Stead L. Understanding statistical tests in the medical literature: which test should I use? Int J Emerg Med. 2008;1(3):197-9. https://doi.org/10.1007/s12245-008-0061-z

30. Byrne BM. Adaptation of assessment scales in cross-nationa research: Issues, guidelines, and caveats. Int Perspect Psychol Res Pract Consult. 2016;5(1):51-65. https://doi.org/10.1037/ipp0000042 